\title{
A propósito do tratamento dos doentes epilépticos no Hospital Nacional dos Alienados durante os anos de 1912 e $1913^{1}$
}

\author{
Pelo Dr. Jefferson de Lemos \\ Alienista da Assistência a Alienados \\ Arquivos Brasileiros de Psiquiatria, Neurologia e Medicina Legal, Rio de Janeiro, n.6, 1915, p.431-459.
}

\section{u u UUU}

Essas indicações sobre a teoria positiva da moléstia que acabamos de fazer, embora sumárias e deficientes, já nos permitiam abordar a interpretação positiva dos sintomas epilépticos. Antes, porém, sentimos a necessidade de nos deter em algumas considerações ainda gerais sobre a concepção da origem da moléstia e seus sintomas, a fim de afastar algumas objeções que possam surgir.

É preciso, antes de mais, ter em vista que a teoria positiva da moléstia, como toda a concepção abstrata, é uma representação aproximada da realidade, e não pretende representar a realidade de modo absoluto. ${ }^{2}$ Esta teoria resulta de uma grande construção sintética para a qual concorreram todos os dados concernentes ao mundo e ao homem, o que mostra a complexidade da concepção e a relatividade com que deve ser considerada. Para reconhecer essa relatividade basta recordar que o estado de completa unidade, tanto individual como coletiva, é um estado ideal, um limite para o qual tende constantemente a espécie humana, à medida que se aperfeiçoa. ${ }^{3}$

Pode-se, pois, considerar sempre o homem como intermediário entre dois termos extremos, um inferior, em que se aproxima do animal, e outro superior, em que ele tende a se aproximar dos tipos realizados pelas melhores naturezas. A observação mostra que os animais, mesmo os das raças domesticadas, adoecem menos e apresentam menor gravidade e diversidade de sintomas do que o homem. No entanto, desde as aves, todos os vertebrados têm os mesmos órgãos cerebrais e corporais que possuímos ${ }^{4}$. São todos influenciados pelos mesmos agentes exteriores que atuam

N.E. - Sobre este artigo, ver "O grande mal no Cemitério dos Vivos: diagnósticos de epilepsia no Hospital Nacional de Alienados”, de Margarida de Souza Neves, neste número de História, Ciências, Saúde - Manguinhos.

${ }^{1}$ Continuado do no II do corrente ano. 1915

${ }^{2}$ Não há mesmo nenhum meio de representar a realidade de modo absoluto.

${ }^{3}$ Necessário se torna, pois, conceber a intensidade e a diversidade dos sintomas e, portanto, sua gravidade, como suscetíveis de se modificarem na medida do desenvolvimento deste estado da unidade individual e coletiva.

${ }^{4}$ V. Lettres sur les animaux de George Leroy. 
sobre nós. A explicação do fato só pode ser encontrada na falta de vida social que eles não têm, ou só têm em grau muito pequeno. "Privés du mouvement social, ces cerveaux foctionnent beaucoup moins, et d'ailleurs réagissent moins sur les viscères nutritifs".

Por outro lado, vemos as naturezas mais socialmente ativas e enérgicas, e principalmente os melhores tipos de altruísmo, resistirem de uma maneira admirável às vicissitudes as mais inconcebíveis, sem adoecerem. Como conciliar estas duas observações que parecem contradizerem-se? Só admitindo, como ensina a doutrina positivista, que o estado moral é o centro de toda a questão, é dele que tudo depende: ele é a origem do bem e do mal, considerado nos resultados de nossa vida social; é também a origem da saúde ou da moléstia, considerado nas suas relações com a nossa vida orgânica, pessoal.

Nos animais ferozes dominam francamente os instintos egoístas: ou eles estão em agitação passageira para satisfazer qualquer dos instintos fundamentais de conservação própria ou da espécie, ou ficam em ignóbil torpor. ${ }^{6}$ Neles não existe propriamente unidade, porque não há meio de disciplinar os instintos egoístas senão pelo altruísmo que é neles muito precário.

O estado social, porém, só pode subsistir mediante os deveres altruístas de cada um para com todos. O indivíduo não pode viver mais só para si, e sim tem de viver também para outrem. Estabelece-se assim uma luta contínua entre o egoísmo e o altruísmo, luta mais ou menos angustiosa, sem tréguas, conforme a natureza moral dos indivíduos. Esta agitação moral só termina, ou antes, só se abranda, à medida que se vai estabelecendo o ascendente decisivo do altruísmo, pela evolução do indivíduo e da espécie, isto é, à medida do desenvolvimento moral e social gerais, que tem por fim o estabelecimento da unidade individual e coletiva. Compreendese bem, pelo que já ficou dito, como esta instabilidade cerebral, determinada pela agitação moral contínua, deixa o organismo em estado de maior ou menor predisposição à moléstia. Pois bem. À medida que o indivíduo se aproxima do tipo moral superior, o que se tornará cada vez mais fácil com os progressos da organização social, esta agitação tende a desaparecer, e a sua resistência às perturbações do exterior torna-se cada vez maior.

O homem comum não sendo nem animal, nem santo, ou antes, participando da natureza de ambos, há de viver em contínuos conflitos afetivos, em uma luta muitas vezes desesperada entre o egoísmo, e o altruísmo, o que ainda é acrescido pela fiscalização contínua da inteligência, que o deixa a todo momento entregue aos martírios do remorso. Este estado afetivo acaba perturbando toda a estabilidade cerebral e corporal, do que pode resultar desde logo a moléstia, ou então, em grau menor, apenas um estado de predisposição que deixa por sua vez o organismo à mercê das perturbações exteriores.

Só a desordem moral deve ser, pois, considerada como a origem de todas as perturbações orgânicas.

As influências exteriores, quer físicas, quer sociais, devem ser tomadas em consideração, a fim de se conceber o problema humano em toda a sua generalidade. Mas o problema propriamente médico pode ser concebido reduzindo-se os fenômenos ao dualismo entre o cérebro e o corpo, isto é, às relações entre o físico e o moral.

\footnotetext{
${ }^{5}$ V. Augusto Comte, Deuxiéme lettre.

${ }^{6}$ A. Comte, Catecismo positivista, ed. brasileira, trad. e anotada por Miguel Lemos, pág.50.
} 
Pode-se, pois, de acordo com as indicações das cartas de Augusto Comte, construir um quadro reunindo todos os fenômenos da moléstia. Em primeiro lugar se há de separar a origem dos sintomas. A origem será distinguida conforme for altruísta (quase sempre por falta) ou altruísta (quase sempre por excesso), fazendo-se as outras subdivisões da origem egoísta ou altruísta, de acordo com os respectivos órgãos. Os sintomas serão divididos em cerebrais e corporais. Os primeiros podem ter por sede os órgãos da inteligência (diversas formas de loucura ou de idiotia), ou os do caráter (atividade), que quase sempre se combinam com os primeiros. Os corporais serão separados também conforme tiverem por sede os órgãos da vida animal ou os da vida vegetativa. Os da vida animal se dividem segundo os órgãos da sensibilidade e os do movimento. Os da vida vegetativa, segundo os da conservação do indivíduo e os da conservação da espécie; aqueles serão subdivididos de acordo com as cinco grandes funções vegetativas já referidas, e os outros, de acordo com os órgãos sexuais e os da maternidade. As cinco funções vegetativas comportam ainda as outras subdivisões.

\section{f $F$}

Esta origem cerebral, ou mais propriamente, moral, da moléstia, que constitui o ponto capital da teoria positiva que aqui sumariamente explanamos, está, porém, longe de ser admitida pelas teorias médicas hoje professadas nas academias. É certo que todos os médicos práticos reconhecem que muitos sintomas a que chamam moléstias são originados de perturbações morais, de emoções mais ou menos violentas ou frequentes, etc., e procuram, sempre com a habitual minúcia e exclusivismo, descobrir quais as moléstias ou sintomas que se ligam a tais ou quais estados morais. Estas observações limitam-se ainda, quase sempre, aos sintomas cerebrais ou então aos corporais da vida animal, a que chamam nervosos ${ }^{7}$, afastando-se quase sempre, como alheios àquela influência, os sintomas vegetativos. Mas quem manuseia os tratados de medicina mais correntes e de mais voga entre os médicos, evidencia logo como é ainda a medo que se ousa incluir um tal elemento da etiologia dos sintomas, e quando estão ainda longe destes apanhados, da concepção sobre a verdadeira origem da moléstia.

Que se descubra, porém, um parasita (pouco importa o tamanho), determinando moléstia. Que se constate a coincidência do aparecimento de certos sintomas com a ingestão deste ou daquele alimento, sólido ou líquido. Que se verifique que uma queda ocorrida de um certo modo deu lugar a uma qualquer manifestação sintomática. Saem então todos a campo para verificar (quando não demonstrar) se toda queda dada de um certo jeito pode determinar, sempre tal ou qual sintoma. Se uma certa moléstia, o beribéri, por exemplo, provém do abuso de arroz. Se um certo micróbio não é capaz de determinar sempre a mesma moléstia, etc. Ou então se generalizam fatos isolados e saem daí teorias mais ou menos extravagantes, em que se procura referir todas as moléstias a um só elemento, quer à natureza da alimentação, sólida, líquida ou gasosa, quer à falta de exercício corporal, quer à deficiência das digestões, etc., e a que é aceita pela maioria dos médicos, a generalização microbiana. O erro provém sempre dos mesmos motivos: de um lado, o ponto de vista do detalhe, a minúcia em concepções que só comportam vistas sintéticas, e de

\footnotetext{
${ }^{7}$ Tal denominação conviria, aliás, tanto à vida animal como à vegetativa, porque uma não dispensa menos do que a outra o concurso dos respectivos nervos para o seu regular funcionamento.
} 
outro, a maneira de raciocinar materialista que consiste em pretender explicar os fenômenos superiores pelos fenômenos inferiores.

Ora, a concepção positiva da moléstia, como toda concepção positiva, deve ser considerada com um grande relativismo. Estas questões todas só podem mesmo ser bem compreendidas dentro das grandes linhas, que só são compatíveis com a grandeza do assunto. Eis porque, aos médicos muito imbuídos já da teoria microbiana, poderá parecer incompatível a teoria positivista com a natureza parasitária de algumas moléstias, pois que a origem moral delas se afiguraria dificilmente explicável.

É preciso, porém, ter bem presente que o dualismo em medicina reduzindo-se sempre às relações entre o cérebro e o corpo, e a presidência no consenso orgânico cabendo ao primeiro, há de se reconhecer que nenhuma influência corporal, mesmo quando ultrapassa os limites normais de variação, pode provocar moléstia sem primeiro romper a unidade cerebral que se reduz, em última análise, ao equilíbrio afetivo. Mas ainda um argumento: os micro-organismos não estão dentro destas condições normais da nossa existência, destes elementos exteriores que são, para a nossa natureza, o alimento, o estimulante e o regulador. Eles atuam acidentalmente e podem esmagar-nos como nos esmagaria uma pedra que sobre nós caísse com uma suficiente massa ou velocidade. Eles atuam ainda como atuaria um veneno que nos fosse injetado na corrente circulatória. Mas em que se alterou a concepção positiva? Também ninguém seria capaz de pôr em dúvida as leis de Kepler sobre a gravitação planetária porque um cometa viesse alterar de qualquer modo, como um acidente perfeitamente possível, o nosso sistema solar, e antes, dentro das alterações que ele determinasse, ainda se haviam de encontrar elementos que comprovassem a realidade daquelas leis.

O que é, entretanto, incontestável, é que só em casos excepcionais a ação desses microorganismos é assim tão insólita, e o ascendente que guarda o organismo humano, mesmo em face desses elementos organizados se verifica sempre, porque em condições exteriores que são evidentemente idênticas em relação a eles, a maioria das pessoas fica indene. As teorias médicas atuais reconhecem mesmo esta necessária predisposição individual; mas ainda a concebem materialistamente.

O papel capital, que neste como nos outros casos, cabe ao estado moral do indivíduo é, porém, iniludível. Lembraremos o que já foi dito a respeito do desenvolvimento epidêmico depois da rotura do laço católico-feudal no XIII século, inclusive do cólera, que é tido como uma das manifestações de parasitismo microbiano indiscutível. Esta última epidemia costuma mesmo seguir quase sempre as calamidades guerreiras, quando a depressão moral se apodera das populações. Mas basta para evidenciar esta verdade a observação comum, que mostra as naturezas ativas e abnegadas resistindo às epidemias mais mortíferas, que vão ceifando os fracos e os tímidos. Não se pretende, porém, negar que, conforme as condições do ataque e a natureza do agente, mesmo as organizações morais mais bem constituídas possam ser afetadas. Mas é certo que só o serão muito mais dificilmente, e uma vez atingidas resistirão muito mais eficazmente. Não há, pois, no fundo, nenhuma diferença essencial em relação às reações do organismo, entre o parasitismo microbiano e os outros agentes físicos. 
Resumindo. O dualismo médico se reduz, como já tivemos ocasião de dizer, às reações entre o físico e o moral, e neste último, à oposição entre o egoísmo e o altruísmo. E como nos órgãos corporais não existe propriamente dualismo, pois que todos eles concorrem para o mesmo fim, a conservação do indivíduo, salvo o episódio da conservação da espécie, havemos de reconhecer que toda a instabilidade que a parte física apresenta provém, na quase unanimidade dos casos (dentro dos limites das nossas condições de existência), da instabilidade moral. Fica, pois, fora de dúvida que sempre que houver um grande equilíbrio moral altruísta que se pode resumir na subordinação do instinto conservador à bondade, a estabilidade física há de acompanhar a estabilidade cerebral. Mas por outro lado, esta mesma estabilidade corporal, embora em proporção menos vantajosa, há de se verificar quando o indivíduo não tiver lutas morais, por um excessivo egoísmo, que lhe apaga mesmo qualquer manifestação de remorso, como sucede geralmente com os piores criminosos. Nestes casos estamos diante de uma verdadeira aberração da natureza humana, que saiu do seu tipo para tornar-se semelhante ao animal. A moléstia pode, então, ser originada ainda pelos instintos egoístas mal contidos, o ódio, o desprezo, a revolta contra a sociedade que põe peias à cobiça, à sanha, à inveja, à ambição.

As naturezas altruístas e enérgicas, porém, que esquecem a sua própria existência para se dedicarem inteiramente a outrem, e cuja resignação lhes acalma todos os sofrimentos próprios a fim de não derramá-los em torno de si, a estas, o desequilíbrio moral só poderá provir de grandes motivos sociais, verdadeiras catástrofes. Mas ainda aqui, apesar do grande abalo produzido, a estabilidade cerebral, e portanto corporal, fica até certo ponto garantida, porque então o indivíduo se sente bem ligado ao passado e ao futuro pela dupla placenta cerebral. ${ }^{8} \mathrm{O}$ presente pode ser sempre considerado como atuando do mesmo modo que o mundo exterior, e a esperança jamais abandona a quem tiver a fé cientifica, isto é, a quem conhecer o conjunto da ordem universal.

É preciso, entretanto, nunca esquecer, na apreciação dos casos particulares, todas as influências que agiram em cada caso que se considera, não só no momento como em toda a vida do indivíduo, e portanto, a suscetibilidade orgânica não só física como cerebral, não só adquirida como hereditária, condições essas que pesam sempre, sobretudo na atualidade, em que a instabilidade social é tão grande, em que os motivos de decepção, mesmo altruísta, são tão fortes, e em que uma tara tão pesada atinge cada um de nós.

\section{f $F$}

Tendo chegado à ocasião de nos reportarmos a parte especial dos aditamentos ao nosso relatório, vamos ainda abandonar os detalhes, tocando apenas nos pontos capitais do assunto. Não entraremos também em discussões sobre tanto que já se tem dito sobre a epilepsia. Vamos tentar uma rápida exposição da concepção positiva a respeito dos sintomas epilépticos, referindonos, a uma ou outra observação particular ou geral que se nos possa ter deparado. E teremos atingido o fim principal que aqui temos em vista, se conseguirmos chamar a atenção dos que porventura nos lerem, para uma doutrina que, segundo nossa profunda convicção, é a única capaz de resolver todos os grandes problemas afetivos, intelectuais e práticos que têm sido levantados pela aspiração geral de todos os séculos.

\footnotetext{
${ }^{8}$ V. Cartas de Augusto Comte sobre a moléstia.
} 
A primeira questão a pôr-se é relativa à sede dos sintomas epilépticos. A necessidade de aceitar uma sede para os sintomas quaisquer é mesmo tão importante, a fim de se não cair no vago metafísico, que Augusto Comte fez sentir que, a este respeito, seria ainda preferível conceber uma sede errada do que não conceber nenhuma. ${ }^{9}$

A teoria positiva do cérebro esclarece-nos, porém, de um modo decisivo sobre as sedes dos sintomas cerebrais da moléstia. A propósito da epilepsia, como dissemos já, é na obra do Dr. Audiffrent ${ }^{10}$ que nos inspiramos, tirando daí os argumentos que levam a estabelecer a sede de seus sintomas.

"O sintoma mais constante que apresenta a moléstia, o que se encontra tanto nos acessos do grande como nos do pequeno mal, na forma convulsiva como na forma vertiginosa, é a perda dos sentidos (supressão das relações com o exterior) e o esquecimento completo de tudo que sucedeu durante o acesso. Este sintoma que não encontramos nem na coreia ${ }^{11}$, nem no tétano, nem em nenhuma outra afecção da medula, é sempre patognomônico de uma moléstia do cérebro. A perda dos sentidos supõe sempre um violento abalo cerebral que torna impossível todo ato de vontade, que se opõe ao estabelecimento de qualquer noção, e, por conseguinte, à sucessão de todas as operações cerebrais de que resulta a memória." ${ }^{12}$

A manifestação epiléptica que domina todas as outras pela sua intensidade, é o grande ataque convulsivo. Todos os músculos da vida animal ficam excitados no máximo grau, e a excitação estende-se aos músculos da vida vegetativa, podendo ir até à tetanização do coração, com morte súbita. A sede cerebral desses sintomas deve assim ser procurada nos órgãos da atividade (caráter), e especialmente nos órgãos que excitam os movimentos, isto é, os órgãos da coragem. A epilepsia resulta, pois, de uma irritabilidade tal desses órgãos que os leva ao mais alto grau de excitação ${ }^{13}$, que não só abala intensamente todo o sistema muscular, nos acessos do grande mal, mas é ainda suficiente, num grau menor de excitação, para determinar os sintomas cerebrais observados nos acessos do chamado pequeno mal.

Aceita a sede indicada como o ponto de partida dos sintomas de epilepsia, tudo o mais nesta moléstia vai encontrar uma racional explicação, o que, por sua vez, constituirá uma confirmação do fato positivo. Já foram referidos os fenômenos da perda dos sentidos e da memória. Eis como o Dr. Audiffrent explica os fenômenos do automatismo:

\footnotetext{
${ }^{9}$ V. Système de Politique Positive, Appendice général, Examen du traité de Broussais sur l’irritation, pág. 223.

${ }^{10} \mathrm{~V}$. Maladies du cerveau et de l’innervation, págs. 540 a 561.

${ }^{11}$ A Coreia deve, pois, ser considerada como uma neurose, porque se trata de uma afecção dos aparelhos da vida animal (medula, núcleos nervosos centrais, etc.). Não há razão também para distinguir entre as coreias verdadeiras e falsas, como nenhum outro sintoma. A moléstia ou existe ou não existe, e as únicas diferenças que podem ser admitidas em sintomas idênticos residem na intensidade maior ou menor deles. Não há moléstia sine materia, como admitiam os antigos. As variedades observadas dependem da extensão das regiões atingidas, ou são relativas à natureza individual de cada doente. Os ticos são coreias reduzidas a uma zona muito limitada, a um determinado núcleo nervomotor.

${ }^{12} \mathrm{O}$ fenômeno da perda de memória, com ou sem perda dos sentidos, tem sido muitas vezes observado por ocasião de abalos cerebrais violentos, de origem moral ou não.

${ }^{13}$ Devemos lembrar que pode haver excitação sem irritabilidade, a excitação sendo um fenômeno perfeitamente normal, enquanto que a irritabilidade é já um grau doentio da excitação.
} 
"Dissemos que se encontram doentes que podem agir, caminhar, ir, vir, no curso de um acesso vertiginoso de epilepsia; fizemos além disso notar que outros podem ainda falar, quando são vivamente interpelados, sem saberem, todavia, o que respondem. Os doentes desta espécie não conservam nenhuma lembrança do que fizeram durante o acesso. Admitimos que nestes doentes, pelo só fato da moléstia, isto é, pelo estado de superexcitação em que se acha o órgão que preside a todos os movimentos, existe uma necessidade insólita de atividade, que os leva irresistivelmente a agir. Que se note bem que é na forma vertiginosa da moléstia que se constata esta disposição irresistível à ação. Na forma convulsiva a crise é muito aguda, muito violenta, para permitir a liberdade dos movimentos. A superexcitação muscular, neste último caso, é tal que os músculos ficam vivamente contraídos durante os dois ou três minutos que dura o ataque.

No caso que examinamos o estado de superatividade dos primeiros órgãos da região ativa é muito grande sem dúvida, para comportar um ato de vontade; entretanto não o é bastante para impedir a locomoção ou a palavra. Neste caso, um conjunto de movimentos coordenados para uma destinação qualquer poderá, entretanto, em virtude do hábito, dar lugar a atos que o indivíduo não teria jamais chegado a executar, se ele tivesse podido presidi-los. Eis como pode suceder que um indivíduo vivamente interpelado possa responder, sem ter, todavia, consciência do alcance de suas palavras e sem mesmo conservar, nestes casos, a lembrança dos atos a que se entregou durante o acesso. É alguma coisa de análogo ao que se passa no sonambulismo, como o faremos ver no capítulo seguinte. Os discursos injuriosos que fazem os doentes, durante a crise vertiginosa, as invectivas que dirigem aos que deles se acercam, mostram qual é a reação do órgão excitado sobre o da destruição". ${ }^{14}$

Um outro fenômeno muito comum nos epilépticos consiste nas perturbações da palavra que se manifestam por uma dificuldade de expressão que pode ir até a inaptidão completa (mutismo) que quase sempre se estabelece nos graus avançados da moléstia. Muitas formas de afasia, passageiras ou permanentes podem, pois, ser observadas. Este fato resulta das ligações diretas que têm os órgãos dos sinais com a região da atividade. ${ }^{15}$ Como já tivemos ocasião de ver, a propósito da teoria cerebral, a inteligência só se liga à atividade por intermédio desses órgãos. Neles é que, incontestavelmente, se fará sentir a primeira e principal influência das desordens epilépticas sobre a inteligência. As perturbações da memória têm mesmo por fundamento, em muitos casos, uma alteração dos órgãos dos sinais, e a dificuldade de expressão, por seu lado, se liga frequentemente a um defeito da memória, provenha ele de onde provier. ${ }^{16}$ Por essas razões, a linguagem do epiléptico se apresenta modificada, mas podendo ser constatados alguns tipos mais comuns: ou as palavras são arrancadas como por um grande esforço, ou são emitidas explosivamente, ou então a frase é arrastada e o epiléptico fala como que cantando tristemente,

\footnotetext{
${ }^{14}$ Dr. Audiffrent, op. cit., págs. 552-553.

${ }^{15}$ Ignoramos se alguma vez já se fizeram referências a estas alterações da linguagem, ligando-as à natureza mesma da epilepsia. Acreditamos, no entanto, que elas possam ser num ou noutro caso reconhecidas como único fenômeno indicativo de um organismo predisposto à epilepsia.

${ }^{16}$ Lembraremos que a integridade da memória resulta do concurso normal das cinco faculdades intelectuais: a contemplação concreta e a abstrata, a indução e a dedução, e a expressão (órgão dos sinais falados, escritos, mímicos, etc.).
} 
como em contínuo queixume. ${ }^{17}$ Quanto às alterações que sobrevêm nos músculos, como atrofias, paralisias, miastenias, assim como a progressiva afecção geral da inteligência e do caráter, observada à medida que os sintomas epilépticos se agravam, e que podem ir até a idiotia completa e à abulia, encontrarão uma tão fácil explicação na natureza de epilepsia, revelada pela teoria cerebral, que não é mister insistir.

Os epilépticos são ainda sujeitos, em períodos mais ou menos longos, a um quebramento de forças extremas, que invade todo o organismo; o cérebro se entorpece, os músculos se afrouxam, e a vida vegetativa, enlanguece. Uma morte próxima parece ser o epílogo deste quadro. Mas o repouso no leito e um regime alimentar adequado bastam para superar a crise.

Relativamente ao fenômeno denominado aura, que é uma manifestação sensorial de qualquer um dos oito aparelhos dos sentidos, pode-se constatar que na epilepsia a sensação parte mais comumente dos membros, determinada pelo sentido da musculação.

Um fato da maior importância para a interpretação dos sintomas da epilepsia e que vem ainda confirmar a sede cerebral que foi indicada para estes sintomas, é a exaltação do instinto destruidor, que acompanha quase sempre o epiléptico e que, às vezes, ultrapassa tudo que se possa imaginar. Esta exaltação resulta não só da relação de função que existe entre o órgão da coragem e o da destruição, como também da sua contiguidade cerebral ${ }^{18}$ :

"Todo ato que reclama uma vontade enérgica, em virtude mesmo dos obstáculos que é preciso muitas vezes afastar e até derrocar, exige a intervenção do instinto destruidor, que tivemos de supor em uma estreita dependência para com o órgão da coragem. Ora, nesta disposição à cólera, à destruição que se constata tão frequentemente durante certos acessos próprios à forma vertiginosa, não é preciso ver uma reação da coragem sobre o instinto destruidor?". ${ }^{19}$

Não é, porém, só durante os acessos da forma vertiginosa que se observa esta disposição moral dos epilépticos. Este estado mental lhes é até muito constante, mesmo fora desses acessos. É frequentemente a única manifestação das formas chamadas larvadas. Quem já privou com epilépticos nos manicômios, onde toda a natureza moral se expande livremente, sabe quanto são rixosos e imperativos em suas vontades. Como nota o Dr. Audiffrent, eles formam nos hospícios uma categoria à parte, e importunam os enfermeiros e os médicos com insaciáveis reclamações.

Na vida social comum, porém, nem sempre se encontram estas más disposições nos epilépticos. É que as reações do meio, as conveniências, os deveres sociais, obrigam-nos a uma disciplina contínua. Também aí raramente encontramos estas formas graves tão comuns nos hospícios. A tendência neles é mesmo para uma melhora progressiva, ao inverso do que se observa no outro caso. Este fato mostra bem até que ponto uma educação bem dirigida pode concorrer para modificar favoravelmente estes terríveis sintomas.

\footnotetext{
${ }^{17}$ Este fenômeno é tão característico, que só por ele temos já chegado a descobrir a epilepsia em pessoas nas quais ignorávamos por completo o terrível sofrimento.

Estas perturbações da palavra, bem observadas, talvez possam servir como meio de diagnóstico das epilepsias chamadas larvadas, e portanto, como sinais capazes de nos levar a prevenir a explosão interior de sintomas mais graves.

${ }^{18}$ A proximidade maior ou menor dos diferentes órgãos está sempre ligada à similitude de suas funções.

${ }^{19}$ Dr. Audiffrent, op. cit., pág. 551.
} 
Relativamente à origem da epilepsia, como em toda a alteração da saúde, é nas desordens afetivas que ela deve ser procurada. Este fato não exclui, é claro, a influência incontestável que tem a reação dos outros órgãos na determinação dos sintomas epilépticos. Uma vez estabelecida, porém, a disposição à epilepsia, a irritabilidade maior ou menor dos órgãos da coragem os deixará sujeitos, em maior ou menor grau, às excitações provenientes de quaisquer dos outros órgãos corporais ou cerebrais.

A origem moral da moléstia é mesmo mais facilmente constatável em relação aos sintomas cerebrais, do que aos vegetativos; mas ainda mais evidente quando se trata de uma afecção dos órgãos do caráter, como é o caso da epilepsia, do que quando os sintomas provêm dos órgãos intelectuais (loucura ou idiotia). Se é verdade que não podemos pensar nunca como se o sentimento não existisse, e muito ao contrário, a natureza dos nossos pensamentos indica sempre quais os sentimentos que estão em jogo, é também certo que o resultado de nossa atividade acha-se ligado de tal modo ao estado de nossos sentimentos (e tanto mais quanto mais espontânea é a ação), que no sexo masculino as duas palavras de caráter e sentimento se confundem numa mesma significação. A ação tende a seguir-se logo ao impulso afetivo. A inteligência só intervém para examinar a sua conveniência, e esclarecer as condições de sua realização.

Compreende-se que, desde que exista uma irritabilidade afetiva num certo grau, que há de provir, na grande maioria dos casos, dos órgãos egoístas mais enérgicos, o instinto conservador, o sexual e o destruidor, e principalmente deste último, cujas relações com os órgãos do caráter já foram indicadas, compreende-se dizíamos, como estes podem acabar por participar com alguma facilidade da irritabilidade dos primeiros. ${ }^{20}$

Dada a natureza ativa do sexo masculino, no qual os órgãos da coragem tomam grande preponderância, a ponto de só se poder imaginar a sua deficiência como uma infelicidade digna de lástima, sente-se bem a que grau pode atingir a desordem que eles determinam sobre o

\footnotetext{
${ }^{20}$ Muitos fatos observados podem servir de confirmação a esta origem afetiva da epilepsia. Assim os terrores noturnos das crianças que às vezes precedem as manifestações epilépticas. As que coincidem com grandes abalos morais, a sustos, terrores, desgostos fortes. A eclampsia infantil, comumente ligada a desordens digestivas; estas atuam sobre os órgãos do caráter através do instinto conservador. Por outro lado, os epilépticos são muito sujeitos a perturbações do aparelho digestivo. As aberrações sexuais têm sido observadas muitas vezes ligadas a disposições epilépticas. Como faz notar o Dr. Audiffrent, o ato sexual assemelha-se mesmo a um acesso de epilepsia. As aberrações do instinto destruidor são então tão comuns, que quase não poderíamos conceber a epilepsia sem elas. A seguinte observação mostra até que ponto pode chegar a exaltação do instinto destruidor, que neste caso se associou à exaltação do instinto nutritivo: "No hospital de Jermo (Estados do Papa) acha-se encerrado um epiléptico há 4 anos, que depois de haver tido verdadeiros ataques de furor, foi acometido de um desejo violento de comer carne humana. Um dia arrancou com os dentes a face toda de um menino. Fugindo do hospital foi para sua casa. Encontrando aí um filho de 2 anos, que dormia, lança-se sobre ele e lhe devora as nádegas, o peito e as coxas; o desgraçadinho morreu três dias depois.O terrível epiléptico surpreendido por sua mulher, fugiu para o campo. Voltando à sua casa, lança-se sobre sua mulher, esta lhe resiste com energia; mas o marido apodera-se de um filho de 5 anos que a mãe trazia nos braços. Trava-se um violento combate e o menino salvou-se. O desgraçado pai de família foi subjugado, amarrado e conduzido à prisão, donde foi transportado para o hospital" (Le Progrès medical, 19 de Julho de 1873, cit. pelo Dr. Audiffrent, op. cit., pág. 55). No Hospício temos muitos doentes que manifestaram esta exaltação destruidora. Um deles, P.R. de C., em um dos seus acessos, armandose de um facão, agrediu a pessoas de sua família e a outras que acudiram em auxílio desta, matando ao todo 7 pessoas, inclusive o pai, e ferindo mais ou menos gravemente quatro. Depois de internado no hospício ainda assassinou dois doentes.
} 
conjunto de nossa economia, uma vez que foram afetados. A reação sobre o instinto destruidor torna-se então das mais funestas consequências.

Constituída a disposição epiléptica, qualquer excitação dos outros órgãos, corporais ou cerebrais, poderá despertar a sua irritabilidade e a série dos sintomas epilépticos. Mas nem por isso a epilepsia deixa de ser, em qualquer caso, evidentemente moral, de origem embora, muitas vezes, só muito remotamente possa ser encontrada esta origem.

Posta a questão nesses termos, ficam unificadas todas as observações que tem sido feitas e nas quais se tem atribuído causas as mais variadas para estes sintomas. Imaginar porém, toda a epilepsia como provocada exclusivamente por esta ou aquela causa, ou conceber uma epilepsia diferente para cada elemento que a determinou, seria evidentemente contrário à verdadeira teoria da natureza humana. A discussão relativa às epilepsias essenciais e sintomáticas fica também afastada para se reduzirem todas as diferenças a simples questões de grau.

Perguntar-se-á, talvez, porque em uns casos a desordem afetiva origina a epilepsia, em outros a catalepsia ou a abulia ${ }^{21}$, do mesmo modo que poderia ainda originar a loucura ou a idiotia, ou uma mielite, ou apenas sintomas vegetativos? Estas questões escapam inteiramente a qualquer explicação científica porque entram no domínio dos fatos concretos. Podemos apenas constatá-los dizendo que tais ou tais órgãos eram o ponto fraco do organismo, o locus minoris resistentiae. Pode-se também constatar que a gravidade dos sintomas aumenta à medida que se sobe dos fenômenos vegetativos para os fenômenos cerebrais, tanto nos estados agudos como nos estados crônicos. ${ }^{22}$

\section{f $F$}

A concepção positiva da epilepsia permite ainda aproximar sintomas que têm sido considerados como de natureza diferente. Assim, a eclampsia puerperal e as convulsões da $1^{\mathrm{a}}$ e $2^{\mathrm{a}}$ infâncias (eclampsia infantil).

A semelhança dessas manifestações com os ataques convulsivos da epilepsia levam a estabelecer para elas a mesma sede sintomática, só existindo, entre todas, diferenças de intensidade e duração que devem ser procuradas nos fatores sexo e idade, e nas circunstâncias ocasionais. Mas essa aproximação é tanto mais natural quanto se tem comumente observado que a epilepsia se estabelece definitivamente em pessoas que tiveram convulsões na infância ou a eclampsia.

Somos aqui naturalmente levados a estabelecer um confronto a fim de indicar entre a epilepsia no homem e na mulher. Esta diferença está na origem e não na sede dos sintomas que é a mesma.

A natureza feminina gira toda em torno da maternidade. Se esta função supõe e exige moralmente o desenvolvimento da bondade, que é sempre tão espontânea na mulher, porque ela tem de proteger e educar o produto que surge do seu seio, o instinto materno que estimula diretamente o desenvolvimento dos germes, não deixa de ser pessoal e, portanto, egoísta. Durante a gestação e em certos períodos da vida da mulher, como na fase da transformação púbere e nos

\footnotetext{
${ }^{21}$ A catalepsia, conforme se pode verificar na obra já citada do Dr. Audiffrent, resulta de uma afecção dos órgãos da firmeza. A abulia (falta de vontade, irresolução) estaria ligada à falta de coragem, ou excesso de prudência. É o que se nota em grau bem pronunciado na melancolia.

${ }^{22}$ Esta observação de Augusto Comte é confirmada pelo seguinte fato: que já deverá ter sido constatado pelos médicos que têm prática nos manicômios: a fragilidade orgânica geral dos alienados que os torna pouco resistentes a quaisquer desordens vegetativas: o restabelecimento destas desordens é difícil, e a mortalidade muito elevada nesses hospitais.
} 
períodos mensais de eclosão ovular, este instinto está sempre em certa exaltação, e a extrema suscetibilidade em que fica o organismo feminino ameaça a estabilidade cerebral, desde que haja ocorrência de certas circunstâncias morais ou mesmo físicas. Os órgãos cerebrais do instinto materno apresentam sempre na mulher um grande desenvolvimento em relação com a grande função feminina. A sua irritabilidade origina os sintomas chamados histeria. Em tese, pode-se mesmo dizer que não há moléstia, na mulher, em que a consideração deste órgão possa ser desprezada. O aforismo médico antigo: mulier tota in utero poderia ser, com maior razão, substituído por este outro: todas as perturbações do organismo feminino partem do instinto materno. Assim também a epilepsia. Os outros fenômenos morais comuns a esta última afecção, como a exaltação dos instintos conservador e destruidor seriam principalmente então considerados como uma reação dos órgãos da coragem irritados.

$\mathrm{O}$ ataque histérico resulta também de uma exaltação desordenada dos órgãos da atividade. Mas há uma diferença entre a epilepsia e a histeria: em uma, é só o órgão da coragem que é extremamente irritável, enquanto que na outra todos os órgãos da atividade ficam em ação, em graus diversos, mas apenas excitados. A prova é que a histérica não perde a capacidade de ação depois do ataque e o epiléptico dos dois sexos fica em torpor mais ou menos longo. (A irritabilidade é um estado funcional que implica alterações anatômicas, embora imperceptíveis.)

As teorias médicas sobre a epilepsia, hoje comumente aceitas, ainda se apresentam muito vagas, ou eivadas de metafísica. Na melhor hipótese já se admite que seja uma afecção cerebral, e se a localiza na região denominada motora, na qual se pretende haver descoberto localizações muito especiais. Admitidas, porém, estas localizações, seria muito natural que encontrássemos epilepsias também muito parciais, da perna, do braço, do pescoço, etc., como se dá com a epilepsia lateral denominada jacksoniana, que se verifica em virtude das localizações cerebrais serem duplas e simétricas. ${ }^{23}$ É muito comum, porém, ainda, explicando os fenômenos nervosos pelos fenômenos elétricos, falar-se em descargas nervosas da epilepsia, etc., ou então em neurose funcional, sem nenhum fundamento anatômico, como se isso fosse possível. Pode-se também constatar a dificuldade que geralmente se encontra para explicar a epilepsia ocasionada por uma lesão cerebral (por exemplo, um tumor) que se desenvolva em outra região cerebral que não seja a motora. A teoria positiva do cérebro e da inervação, assim como a concepção positiva da moléstia respondem, no entanto a todas estas questões obscuras.

Existe hoje uma tendência muito acentuada a ligar-se toda moléstia para a qual não foi ainda encontrada uma explicação microbiana, a uma autointoxicação, quer seja de origem gastrintestinal, quer de origem glandular (glândulas de secreção interna). A epilepsia não escapou a esta explicação, principalmente quanto ao primeiro modo, que é hoje o mais geralmente aceito.

A importância dessas glândulas, que naturalmente desempenham funções que se ligam à nutrição, é incontestável. Já citamos um trecho de Augusto Comte em que está indicado este papel para as glândulas testicular e mamária. Estas têm, porém, uma dupla função, interior e exterior. Outras há cuja função é somente interior. As anomalias de desenvolvimento, quer cerebral, quer físico, já observadas com bastante frequência em consequência da alteração dessas

${ }^{23}$ As paralisias parciais, denominadas monoplegias, são evidentemente de origem medular e não cerebral. 
glândulas parecem mostrar que elas se destinam normalmente a estimular e regularizar este desenvolvimento. Muitas delas perderiam, pois, de importância, à medida que o desenvolvimento orgânico se fosse completando, e outras entrariam em completa atrofia, como se dá, por exemplo, com o timo.

Quanto, porém, às conclusões especialistas a que se tem chegado, na multiplicidade das observações que têm sido feitas, muitas objeções se podem apresentar. Assim, por exemplo, em relação às substâncias que se têm delas extraído, e as quais se tem atribuído a influência delas no organismo. Note-se primeiramente, que as análises feitas em órgãos subtraídos, no entanto, do organismo não podem servir de base para nenhuma apreciação da função deles nas condições normais. Num caso o órgão está morto, no outro caso está vivo. De que modo se poderia provar que as substâncias aí encontradas não resultaram da decomposição do órgão? Por outro lado, supondo mesmo que estas substâncias existissem no órgão vivo, quem poderá afirmar que é neste estado que elas vão agir no fenômeno nutritivo? Poder-se-ia fazer ainda uma hipótese, é que nas condições normais estas glândulas não produzem tais substâncias, que só aparecem quando justamente estão afetados. Mas tudo isso não passa de suposições. Todas estas questões ficam, assim, esperando um melhor julgamento.

\section{f $F$}

Relativamente ao tratamento da epilepsia, pouco temos a acrescentar ao que já dissemos no relatório. A verdadeira medicina consistirá sempre na higiene cerebral e corporal, de modo a impedir que se adoeça. Uma vez, porém, que a saúde se alterou, a primeira condição a preencher é não prejudicar mais ainda as perturbações orgânicas por um cego empirismo. É na subordinação racional às leis naturais de nossa organização que o médico poderá encontrar uma necessária liberdade de ação, sem se arriscar a ser cúmplice inconsciente de uma agravação da moléstia.

Já vimos como o equilíbrio orgânico geral fica dependendo do equilíbrio afetivo. Uma conveniente educação que possa desenvolver os instintos altruístas e comprimir os instintos egoístas constitui, pois, a primeira garantia para a conservação da saúde. Só o altruísmo pode conduzir-nos, ao mesmo tempo, à solução dos três problemas conexos: o do dever, o da felicidade e o da saúde. No caso particular da epilepsia, cujos sintomas são tão funestos para o indivíduo como perigosos para a sociedade, é óbvio que se procura cercar de maiores cuidados ainda as pessoas que tenham manifestado predisposição à epilepsia, e com muita eficácia porque ela se patenteia, na maioria dos casos, na $1^{\mathrm{a}}$ e $2^{\mathrm{a}}$ infâncias e na adolescência. A preexistência da eclampsia infantil e a natureza moral da criança são dois elementos que podem servir de guia na descoberta desta predisposição, além de outros sinais que comumente podem ser verificados nos atos da vida animal e vegetativa.

Temos a firme convicção de que, quase sempre, poderíamos evitar, deste modo, ou pelo menos atenuar, a explosão dos sintomas epilépticos. A tendência para uma acentuada melhoria que têm em geral os doentes observados na clínica civil, contrastando com o oposto que se observa na clínica hospitalar, é já boa demonstração dos resultados que poderão ser obtidos com uma conveniente educação e com os esforços da vontade pessoal dos doentes.

Em segunda linha vem então a higiene física e intelectual: observar um regime alimentar brando e sóbrio, assim como todos os preceitos que levam à regularização da atividade corporal e mental. Já nos referimos, no relatório, ao regime que adotamos quanto à alimentação. 
Cumpre-nos declarar que o empirismo médico tem hoje voltadas as suas vistas para o regime alimentar na epilepsia, como o melhor meio de tratamento que se tem encontrado. Em hospitais europeus esta prática já tem sido realizada, e entre nós, já foi tentada mais de uma vez, no Hospital Nacional de Alienados, com bons resultados, e constitui mesmo, assunto de mais de um trabalho acadêmico (teses e artigos). Não obstante isso, nunca se o empregou com a necessária largueza, pois que a tendência das observações que se tem feito, visa encontrar uma certa espécie de alimento que fosse eficaz em todos os casos de epilepsia. Além disso, desde que não se conheça a verdadeira natureza desses sintomas, esses felizes resultados do empirismo de agora ficam sujeitos a novas alterações. Assim, por exemplo, a preocupação de desintoxicar o organismo, ou de forçar a calma, tem já conduzido a juntar-se sempre à alimentação alguma substância que se considere útil a este fim. Não duvidamos, pois, que dentro de pouco tempo, o regime alimentar seja abandonado no rol das velharias, a fim de deixar o caminho livre para novas tentativas médicas que são intituladas experiências.

O que dissemos, porém, sobre a doutrina positivista, no que respeita à medicina em geral, e à epilepsia em particular, evidencia que o ponto de vista sistemático pode conduzir desde logo, como de fato conduziu-nos, sem nenhuma vacilação, à prática mais racional.

A higiene física e mesmo a mental não podem, contudo, deixar de ser muito secundárias em relação à educação afetiva. E quanto aos outros meios, todos eles são apenas paliativos que podem ser mais ou menos valiosos, e com os quais se pode conseguir a atenuação dos sintomas mais intensos ou aflitivos, mas sem que seja lícito esperar nunca deles uma verdadeira cura.

O valor dos meios morais é, no entanto, incontestavelmente inexcedível, e o que dissemos em relação ao tratamento da epilepsia não é mais que uma aplicação de princípios gerais. Todos os males que hoje afligem a espécie humana desaparecerão no dia em que ela achar-se moralmente regenerada, o que mostra ainda que o problema humano é, fundamentalmente, um problema religioso.

\section{f $F$}

Pelo breve resumo que tentamos fazer das teorias positivas que se relacionam com a medicina, pode-se evidenciar que só na doutrina positivista se há de encontrar a verdadeira filiação de todas as concepções humanas. Já vimos como esta filiação é explicada tão logicamente pela lei dos 3 estados. Toda a dificuldade da evolução do espírito humano consistiu em fazer com que o homem transformasse o modo inicial de raciocinar absoluto, pelo modo relativo final, único compatível com a nossa natureza e a nossa situação. Mas essa difícil evolução, ainda hoje só completamente realizada em poucos espíritos, não era possível sem a descoberta das leis abstratas de todos os fenômenos (conjunto das 7 ciências). Essa intervenção indispensável da inteligência fez com que o orgulho e a vaidade conduzissem a atribuir ao espírito a preeminência que na nossa organização cerebral cabe espontaneamente ao coração (sentimento).

Eis porque, respeitada essa preeminência na idade fetichica (estado espontâneo), foi sendo cada vez mais desconhecida, com períodos de maior ou menor agravação, desde a fase teocrática até nossos dias, determinando uma verdadeira revolta do espírito contra o coração. É esta revolta que caracteriza o estado de anarquia dos tempos modernos, e que tende cada vez mais a agravarse com o especialismo científico. O desfecho de toda a evolução humana ficava assim ligado a cessação dessa anomalia. 
A construção da teoria positiva do cérebro, demonstrando, porém, a necessária subordinação da inteligência e da atividade ao sentimento, veio sistematizar nosso estado espontâneo, relacionando, portanto, o fetichismo com o positivismo. Essa construção representa, pois, o verdadeiro termo da evolução teórica. Desde então a moral estava fundada. A sistematização total da nossa existência, cosmológica, social e individual tornou-se possível, mediante a subordinação de qualquer um de seus aspectos ao ascendente moral, isto é, ao predomínio do altruísmo. Amando tudo que o cerca, o homem desenvolve o amor sobretudo para com seus semelhantes, na Família, na Pátria, na Humanidade. Viver para outrem constitui assim a suprema lei humana. O amor votado ao Grão Ser seletivo sendo, porém, mais vasto e o mais desinteressado, é por isso mesmo o mais digno. Seu culto deve, pois, prevalecer sobre o da Pátria e o da Família. Amar, conhecer e servir a Humanidade, tal é o nosso verdadeiro destino sobre a terra.

\section{f $F$}

Nada poderia demonstrar melhor a falência da inteligência, quando ela pretende gerir os destinos humanos, esquecendo a sua necessária subordinação ao altruísmo, do que esta guerra fratricida que hoje enluta o mundo inteiro.

Todos os países europeus se orgulhavam de sua ciência, de sua arte, de sua indústria; mas toda essa ciência, toda essa arte e toda essa indústria não puderam impedir esta indecorosa explosão.

É que estavam ao serviço da vaidade, do orgulho e da cobiça de seus acólitos, em vez de se acharem subordinadas ao altruísmo, servindo a fraternidade humana. De todas as explicações que se possam dar dessa inqualificável guerra, uma é incontestavelmente certa: ela resultou da incapacidade moral e mental dos atuais estadistas e cientistas ocidentais. É rigorosamente uma verdade que a massa geral dos povos ocidentais, constituída pela mulher e pelo proletariado, condena a guerra. Só, pois, as maquinações dos políticos e das chancelarias, apoiados pela classe dos cientistas especialistas, poderiam conduzir os países europeus a esta cruel catástrofe. Mas tudo isso prova que não existe hoje mais quem governe espiritualmente o ocidente. Desde o XIII século que o regime católico-feudal entrou em progressiva decadência. E perante a tremenda luta atual o Papa só encontrou uma saída, a da neutralidade. Só uma nova religião será capaz de restabelecer, de uma vez para sempre, a paz no mundo e essa religião da Humanidade, com o seu regime social, a sociocracia. A fraternidade universal, esclarecida pela fé cientifica, dirigirá a atividade pacífica. Nenhum preconceito separará mais os homens, nem os de família, nem os de classe, nem os de nacionalidade, nem os de raça. Acima do nascimento acima da posição social, acima de tudo, estão os méritos e virtudes individuais. Quanto às raças, ainda hoje tão mal apreciadas pela raça preponderante, a branca, eis o juízo de Augusto Comte:

O Sacerdote: "A verdadeira teoria biológica das raças humanas resulta, minha filha, da concepção de Blainville, que representa essas diferenças como variedade devidas ao meio, mas que se tornarão fixas, mesmo hereditariamente, logo que atingirem sua maior intensidade. Segundo este principio, pode-se construir subjetivamente uma doutrina essencialmente de acordo com as únicas diversidades verificadas pela apreciação objetiva, que não admite realmente senão três raças distintas, branca, amarela e preta.

Com efeito, as únicas diferenças essenciais e duráveis que se podem ter desenvolvido são as que se referem ao predomínio relativo das três partes fundamentais do aparelho cerebral, 
especulativa, ativa e afetiva. Tais são, portanto, as nossas três raças necessárias, das quais cada uma é superior às outras duas, ou em inteligência, ou em atividade, ou em sentimento, como o confirma o conjunto das sãs observações. Esta apreciação final deve demovê-las de todo desdém mútuo, e fazer-lhes igualmente compreender a eficácia do seu concurso íntimo, para acabar de constituir o Gran Ser.

Quando os nossos trabalhos tiverem saneado uniformemente o planeta humano, estas distinções orgânicas tenderão a desaparecer, em virtude mesmo de sua origem natural, e sobretudo mediante dignos casamentos. A combinação crescente dessas raças nos proporcionará, sob a direção sistemática do sacerdócio universal, o mais precioso de todos os aperfeiçoamentos, aquele que diz respeito ao conjunto de nossa constituição cerebral, assim tornada mais apta para pensar, agir e mesmo amar." ${ }^{24}$

Esta apreciação sobre as raças mostra que não há raças superiores ou inferiores, e sim, apenas raças mais adiantadas ou mais atrasadas em sua evolução. Se a raça branca adiantou-se mais foi porque o progresso social e o desenvolvimento moral dependiam do surto científico, e portanto, da inteligência. Mas se supuséssemos que os representantes de todas as raças desaparecessem, com todos os progressos já realizados, e só restasse a tribo selvagem mais atrasada, esta iria reconstituir toda a evolução por que já passou a espécie humana, nos seus núcleos mais avançados. Ainda mais: conforme uma decisiva sentença de Augusto Comte, se todos os homens desaparecessem simultaneamente da superfície da terra, a espécie animal sobrexistente que se mostrasse superior às outras, constituiria uma nova humanidade, que necessariamente não precisaria ser idêntica sob todos os aspectos, à de que fazemos parte. Esta consideração é suficiente, por si só, para abater o orgulho entre os homens.

\section{f $F$}

Terminando, juntaremos aqui algumas observações individuais:

F.M., 25 anos, mestiça. Entrada para a Seção de epilépticos em Maio de 1911. Ataques quase diários, até 6 por dia; mais comumente, de 2 a 4 . Eis o cômputo mensal, de Junho de 1911 a Abril de 1912: 47-61-42-52-50-50-71-67-64-63-48 - Estava magra, pálida, macilenta. Fácies abatido, triste. Astenia muscular extrema.

Iniciado o tratamento a 17 de Maio de 1912, só teve dois ataques até o fim do mês, e nenhum durante todo mês de Junho. De Julho em diante eis a cota mensal: 6-8-4-4-14-6-9-3-8-7-4-1. Mas desde o começo do tratamento a doente foi adquirindo maior regularidade das funções vegetativas, desaparecendo a astenia, a ponto de poder auxiliar os serviços comuns da Seção.

M.T. de J., 23 anos, preta. Entrada em Agosto de 1911, e submetida ao tratamento conhecido pelo nome de Bechterew. Ataques diários, até 6 por dia; comumente 2 a 4 . Cômputo mensal dos ataques de Setembro de 1911 a Abril de 1912: 34-27-35-25-34-26-52-86. Era excessivamente magra e tão prostrada que quase não se podia manter em pé, e a emissão da voz era-lhe impossível. Fácies triste e aparvalhada.

\footnotetext{
${ }^{24}$ V. Catecismo positivista, 3르 edição brasileira, trad. e anotado por Miguel Lemos, págs. 386 a 388.
} 
Iniciado o tratamento em 17 de Maio, só teve 9 ataques até o fim do mês, e nos meses seguinte, respectivamente 10-8 e 2 até meados de Setembro, quando foi transferida para a Seção Esquirol. Por esta ocasião achava-se mais nutrida, já auxiliava os serviços de seção e os ataques haviam perdido quase toda a feição epiléptica. $\mathrm{Na}$ Seção Esquirol foi submetida ao regime comum, vindo a falecer poucos dias depois por haver sido acometida de ataques violentos e sucessivos (estado de mal).

A. de O.G., 30 anos, mestiça. Na seção de epilépticas desde Janeiro de 1907. Ataques diários; frequentemente, de 10 a 15 por dia. Eis o que apuramos do seu registro clínico:

Nos 9 primeiros meses, em que não há indicação do tratamento seguido, a cota mensal oscilou entre o mínimo de 20 e o máximo de 73 . Em 14 meses em que foi tratada pelos sais de magnésia, oscilou entre 41 e 88 . Dois meses em que foi tratada pela valerobromina, 46 e 51 . Mais de dez meses sem indicação de tratamento, de 33 a 73. Cinco meses sem nenhum tratamento, de 15 a 56 . Com o bromureto de potássio, durante 24 meses, verificaram-se de 15 a 49 ataques entre a máxima e a mínima.

Iniciando o novo regime a 17 de Maio de 1912, só teve 4 ataques neste mês. Daí por diante, eis a apuração mensal: 9-3-3-1-1-5-9-6-4-10-9-6-1-0. Raramente teve mais que 1 ataque num só dia e apenas uma só vez atingiu a 4 .

C.F., branca, 16 anos. Entrada para a seção em Janeiro de 1909. Registro clínico: 8 meses sem menção de tratamento - o número mensal de ataques oscilou entre 7 e 52 . Em 26 meses de tratamento Bechterew, entre 6 e 28. Com bromureto e regime descloretado durante 5 meses, entre 4 e 12 .

Novo regime a 17 de Maio: 2 ataques até o fim do mês, desaparecendo por completo nos meses seguintes, exceto em Setembro de 1912 no qual só teve 3, e Janeiro de 1913 no qual teve 1. Faleceu em Fevereiro, de disenteria.

A.W., 38 anos, branca. Transferida para a seção em Janeiro de 1912.

Tratamento Bechterew durante 3 meses; resultado: 7, 15 e 24 ataques. De maio em diante: 3-10-9-0-0-0-2-1-0-2-4-3-2-6.

Só anotamos aí as doentes mais gravemente afetadas, nas quais o resultado do tratamento se tornou mais evidente. Mas todas as doentes melhoraram, não só quanto ao número de acessos convulsivos, como em sua intensidade. Em nenhum caso foi observada agravação dos sintomas. Eis porque, considerando o conjunto das doentes, pudemos verificar que o número de acessos baixou a quase $1 / 4$ do que era anteriormente ao tratamento.

Para comprovar isto tomamos onze meses antes de instituir o tratamento (porque desde essa época o número de doentes da seção (24) tornou-se quase fixo), e os comparamos com 11 meses seguintes. Os acessos convulsivos orçaram cada mês, no prazo anterior, em: 234-228-300-218242-280-336-286-227-306-324; e depois em 82-94-70-81-72-81-63-75-57-54-90-80-76.

Tomando a média, encontramos 271 para um lado e 74 para outro, o que representa uma redução de quase $3 / 4$, aproximadamente.

Temos, no entanto, a firme convicção de que, se tivéssemos podido realizar este tratamento em melhores condições que não em doentes hospitalizados, ainda os resultados teriam sido muito mais favoráveis. 